\title{
Identifying Business Cycle Turning Points in Real Time
}

\author{
Marcelle Chauvet and Jeremy M. Piger
}

$\triangle 1$ common feature of industrialized economies is that economic activity moves between periods of expansion, in which there is broad economic growth, and periods of recession, in which there is broad economic contraction. Understanding these phases, collectively called the business cycle, has been the focus of much macroeconomic research over the past century. In the United States, the National Bureau of Economic Research (NBER), a private, nonprofit research organization, serves a very useful role in cataloging stylized facts about business cycles and providing a historical accounting of the dates at which regime shifts occur. This task began soon after the founding of the NBER in 1920 and has continued to the present day. ${ }^{1}$ Since 1980, the specific task of dating "turning points" in U.S. business cycles, or those dates at which the economy switches from the expansion regime to the contraction regime and vice versa, has fallen to the NBER's Business Cycle Dating Committee. ${ }^{2}$

The NBER dates a turning point in the business cycle when the committee reaches a consensus that a turning point has occurred. Although each committee member likely brings different techniques to bear on this question, the decision is framed by the working definition of a business cycle provided by Arthur Burns and Wesley Mitchell (1946, p. 3):

Business cycles are a type of fluctuation found in the aggregate economic activity of

\footnotetext{
1 For an interesting history of the NBER's role in defining and dating the business cycle, see Moore and Zarnowitz (1986).

2 There are currently six members of the committee: Robert Hall of Stanford University, Martin Feldstein of Harvard University, Jeffrey Frankel of the University of California at Berkeley, Robert Gordon of Northwestern University, N. Gregory Mankiw of Harvard University, and Victor Zarnowitz of Columbia University.

Marcelle Chauvet is an associate professor at the University of California, Riverside, and an associate policy advisor at the Federal Reserve Bank of Atlanta. Jeremy M. Piger is an economist at the Federal Reserve Bank of St. Louis. The authors thank James Bullard Michael Dueker, James Hamilton, James Morley, and Michael Owyang for helpful comments. Mrinalini Lhila and John Zhu provided research assistance.

(C) 2003, The Federal Reserve Bank of St. Louis.
}

nations that organize their work mainly in business enterprises: a cycle consists of expansions occurring at about the same time in many economic activities, followed by similarly general recessions, contractions and revivals which merge into the expansion phase of the next cycle.

A fundamental element of this definition is the idea that business cycles can be divided into distinct phases, with the phase shifts characterized by changes in the dynamics of the economy. In particular, expansion phases are periods when economic activity tends to trend up, whereas recession phases are periods when economic activity tends to trend down. In practice, to date the transition from an expansion phase to a recession phase, or a business cycle peak, the NBER looks for clustering in the shifts of a broad range of series from a regime of upward trend to a regime of downward trend. The converse exercise is performed to date the shift back to an expansion phase, or a business cycle trough.

The NBER's announcements garner considerable publicity. Given this prominence, it is not surprising that the business cycle dating methodology of the NBER has come under some criticism. Two criticisms that are of primary interest in this paper are as follows: First, because the NBER's decisions represent the consensus of individuals who bring differing techniques to bear on the question of when turning points occur, the dating methodology is neither transparent nor reproducible. Second, the NBER business cycle peaks and troughs are often determined well after the fact. This practice appears to be largely the result of the NBER's desire to avoid calling false turning points.

Of course, the NBER is not the only source of information regarding business cycle turning points. Economists and statisticians have developed many statistical methods that automate the dating of business cycle peaks and troughs (see Boldin, 1994, for a summary). One such technique is the Markovswitching model. This model, popularized by Hamilton (1989) in the economics profession, is capable of statistically identifying shifts in the 
parameters of a statistical process driving a time series of interest. These models are quite simple, making them transparent and reproducible. Also, Layton (1996) provides some evidence that Markovswitching models provide timely identification of business cycle turning points. ${ }^{3}$

In this paper we take it as given that the NBER correctly identifies the dates of business cycle turning points. We then evaluate the real-time performance of the Markov-switching model in replicating the NBER's business cycle dates. We apply the model to two datasets, growth in quarterly real gross domestic product (GDP) and growth in monthly economywide employment. We first confirm the result found elsewhere that the model is able to replicate the historical NBER business cycle dates fairly closely when estimated using all available data. Second, we evaluate the real-time performance of the model at dating business cycles over the past 40 years; this is accomplished by estimating the model on recursively increasing samples of data and evaluating the evidence for a new turning point at the end of each sample.

This approach builds on the exercise undertaken in Layton (1996), extending it in two main ways. First, while Layton used fully revised data in his recursive estimations, here we use "real-time" data. That is, for each recursive sample we use only data that would have been available at the end of the sample period being considered. This method provides a more realistic assessment of how the model would have performed, as it does not assume knowledge of data revisions that were not available at the time the model would have been used. Second, we extend Layton's sample to include the 2001 recession, in order to investigate the properties of the model in the most recent business cycle.

The results of this exercise suggest that the model chooses turning points in real time that are fairly close to the NBER dates. In addition, we find evidence that the model would have identified business cycle turning points faster than the NBER Business Cycle Dating Committee, with a larger lead time in the case of troughs. The switching model achieves this performance with few incidences of false positives. Overall, these results suggest that the Markov-switching model is a potentially very useful tool to use alongside the traditional NBER analysis.

\footnotetext{
3 The Markov-switching approach to dating business cycle turning points has recently received media attention: Kevin Hassett advocated its use on the editorial page of the March 28,2002, edition of the Wall Street Journal.
}

Of course, this line of research is predicated on the assumption that turning point dates are interesting concepts, and some might question whether these dates have any worthwhile intrinsic meaning. We argue that they do. There is much evidence that the two regimes defined by the NBER turning point dates are quite different, beyond the distinction of expansion versus contraction. First, knowledge of which regime the economy is in can improve forecasts of economic activity (see, for example, Hamilton, 1989). Second, there is evidence that the relationship between economic variables changes over NBER-identified phases. For example, McConnell (1998) and Gavin and Kliesen (2002) have shown that the relationship between initial claims for unemployment insurance and employment growth is stronger during NBER-dated recessions. Third, there is growing evidence that fluctuations in output during NBER recession episodes are purely temporary, whereas those during NBER expansion episodes are permanent (see, for example, Beaudry and Koop, 1993, and Kim, Morley, and Piger, 2002). This finding is suggestive of a "plucking" model for U.S. output, in which the business cycle is characterized more by negative deviations from trend output than by positive deviations. ${ }^{4}$ Such a pattern is not generally implied by linear macroeconomic models of the business cycle, suggesting that the NBER dates define interesting economic episodes from a modeling perspective. Finally, the NBER dates, regardless of whether they have intrinsic meaning, garner considerable attention from the media and politicians. Thus, if the economics community is going to produce estimates of turning points, we should be interested in developing accurate, timely, and transparent methods for doing so.

In the next section we provide a review of the Markov-switching model used in this paper. The third section discusses the full sample and "realtime" performance of the model for dating turning points in the business cycle.

\section{THE MARKOV-SWITCHING MODEL OF BUSINESS CYCLE DYNAMICS}

As discussed in the introduction, the NBER definition of a business cycle places heavy emphasis on regime shifts in the process driving economic

\footnotetext{
4 The "plucking" terminology was coined by Milton Friedman (1964, 1993).
} 
activity. In the past 15 years there have been enormous advances in formally modeling regime shifts in a rigorous statistical framework. In a paper published in 1989, James Hamilton developed an extremely useful tool for statistically modeling regime shifts in autoregressive time series models. To understand this model, it is useful to begin with a simple linear time-series framework for the growth rate of some measure of economic activity, $y_{t}$ :

$$
\begin{aligned}
& \left(y_{t}-\mu\right)=\rho\left(y_{t-1}-\mu\right)+\varepsilon_{t} \\
& \varepsilon_{t} \sim N\left(0, \sigma^{2}\right) .
\end{aligned}
$$

In this model, the growth rate of economic activity has a mean denoted by $\mu$. Deviations from this mean growth rate are created by the stochastic disturbance, $\varepsilon_{t}$. These deviations are serially correlated, modeled as an AR(1) time-series process with parameter $\rho$.

Hamilton's innovation was to allow the parameters of the model in (1) to switch between two regimes, where the switching is governed by a state variable, $S_{t}=\{0,1\}$. When $S_{t}=0$ the parameters of the model are different from those when $S_{t}=1$.

Clearly, if $S_{t}$ were an observed variable, this model could simply be estimated using dummy variable methods. However, Hamilton showed that even if the state is unobserved, the parameters of the model in each state could be estimated if one is willing to place restrictions on the probability process governing $S_{t}$. Hamilton derives an estimation technique that could be used to estimate the model when the probability process governing $S_{t}$ is a first-order Markov chain. This stipulation simply means that any persistence in the state is completely summarized by the value of the state in the previous period. Under this assumption, the probability process driving $S_{t}$ is captured by the following four transition probabilities:

$$
\begin{aligned}
& P\left(S_{t}=1 \mid S_{t-1}=1\right)=p \\
& P\left(S_{t}=0 \mid S_{t-1}=1\right)=1-p \\
& P\left(S_{t}=0 \mid S_{t-1}=0\right)=q \\
& P\left(S_{t}=1 \mid S_{t-1}=0\right)=1-q
\end{aligned}
$$

Clearly, conclusions regarding when $S_{t}$ changes may depend on which parameters of the model are allowed to change. For example, the instances when the data may support regime shifts in the variance of the disturbance, $\sigma^{2}$, may be at different times from those in the autoregressive parameter, $\rho$. Thus, if we are interested in using this model for identifying the NBER's turning point dates, we should allow regime switching in those parameters of the model that seem to change from expansion to recession. Hamilton showed that allowing the mean growthrate parameter, $\mu$, to vary with $S_{t}$ seems to be adequate for this task. In particular, Hamilton specified the following augmented version of (1):

$$
\begin{aligned}
& \left(y_{t}-\mu_{s_{t}}\right)=\rho\left(y_{t-1}-\mu_{s_{t-1}}\right)+\varepsilon_{t} \\
& \varepsilon_{t} \sim N\left(0, \sigma^{2}\right) \\
& \mu_{s_{t}}=\mu_{0}+\mu_{1} s_{t} \\
& \mu_{1}<0,
\end{aligned}
$$

where $S_{t}$ depends on the transition probabilities in (2). Here, when $S_{t}$ switches from 0 to 1 , the growth rate of economic activity switches from $\mu_{0}$ to $\mu_{0}+\mu_{1}$. Since $\mu_{1}<0$, the model will estimate these switches at times when economic activity switches from high-growth to low-growth states. Hamilton applied this technique to the growth rate of U.S. gross national product and found the best fit when $\mu_{0}>0$ and $\mu_{0}+\mu_{1}<0$, suggesting the model was capturing regimes when the economy was expanding versus regimes when the economy was contracting. The estimated probability that $S_{t}$ was equal to 1 conditional on all the data in the sample, denoted $P\left(S_{t}=1 \mid T\right)$, corresponded very closely to NBER recession dates. This finding was particularly striking in that Hamilton estimated his model with only one variable describing economic activity.

Since the publication of Hamilton's paper, a large number of alternative Markov-switching models of the business cycle have been studied. Boldin (1994) fits the Hamilton model to an alternative measure of economic activity, namely, the unemployment rate. Other authors, for example, Hansen (1992), allow for regime-switching in parameters other than the mean growth rate, such as the residual variance or autoregressive parameters. The Hamilton model was modified to allow for additional phases in business cycle dynamics by Sichel (1994), Kim and Nelson (1999), and Kim, Morley, and Piger (2002). Finally, building on work by Diebold and Rudebusch (1996), Chauvet (1998) and Kim and Yoo (1995) extended the Hamilton model to a multivariate framework, estimating a coincident index of economic activity with a regime-switching mean growth rate. 


\section{DATING BUSINESS CYCLES WITH THE SWITCHING MODEL}

\section{Model Specification and Estimation}

In this paper we work with the model given in equations (2) and (3), which is applied to two different measures of economic activity for which rich unrevised "real-time" datasets are available. The first is the growth rate of quarterly real U.S. GDP, yielding a model very similar to that originally estimated by Hamilton. The second is a higher-frequency measure of economic activity, monthly nonfarm payroll employment.

The model is estimated using Hamilton's (1989) nonlinear filter. The algorithm provides the conditional probability of the latent Markov state, which permits evaluation of the conditional likelihood of the observable variable. The filter evaluates this likelihood function, which can be maximized with respect to the model parameters using a nonlinear optimization algorithm. The estimation procedure and derivation of the likelihood function are described in detail in Hamilton (1994). Following Albert and Chib (1993), we set the autoregressive coefficient, $\rho$, equal to 0 , a priori. This specification seems best able to replicate the historical record of NBER business cycle dates.

\section{Full-Sample Business Cycle Dates}

Before analyzing the real-time ability of the model to date turning points, we are first interested in their ability to replicate the NBER business cycle chronology using all available data. Thus, we first estimate the model using data on (i) growth in real GDP from the second quarter of 1947 through the second quarter of 2002 and (ii) data on nonfarm payroll employment growth from February 1947 through July 2002. The GDP data are from the July 31 , 2002, release from the Bureau of Economic Analysis, and the employment data are from the August 2, 2002, release from the Bureau of Labor Statistics.

As a first step in evaluating the ability of the model to replicate the NBER turning point dates, consider Figures $1 \mathrm{~A}$ and $\mathrm{B}$, which hold the estimated probability that $S_{t}=1$ conditional on all the data in the sample, or $P\left(S_{t}=1 \mid T\right)$, for both applications of the model. In the graphs, shading indicates NBERlabeled recessions. The graphs suggest that the model captures the NBER chronology fairly closely. During periods that the NBER classifies as expansions, $P\left(S_{t}=1 \mid T\right)$ is usually close to 0 . Near the point where the NBER recession begins, $P\left(S_{t}=1 \mid T\right)$ spikes upward and remains high until around the time when the NBER dates the end of the recession.

Although visual inspection of the probabilities suggests comparability, it is difficult to tell how close the turning points from the Markov-switching model are to the NBER dates without the tabulation of specific dates based on the probabilities produced by the model. To do this, a formal definition is needed to convert the probabilities produced by the switching model into turning point dates. One approach, used by Hamilton (1989) among others, is to classify a turning point as occurring when $P\left(S_{t}=1 \mid T\right)$ moves from below 50 percent to above 50 percent or vice versa. This approach has an intuitive appeal as it separates times when an expansion state is more likely from those when a recession state is more likely. This rule would be problematic if $P\left(S_{t}=1 \mid T\right)$ fluctuated around 50 percent, in which case an excessive number of business cycle peaks and troughs would be called. However, since the Markovswitching model applied to the GDP and employment series produces probabilities that are generally close to 0 or 1 , we adopt this simple definition.

We augment this definition with one of two rules specifying how long a phase must persist before a turning point is identified. For example, suppose $P\left(S_{t}=1 \mid T\right)$ moves from below 50 percent to above 50 percent. Should we immediately declare a business cycle peak has occurred and the economy has entered a recession phase? Or should we require confirmation of the recession phase, by verifying that $P\left(S_{t+1}=1 \mid T\right), P\left(S_{t+2}=1 \mid T\right), \ldots P\left(S_{t+k}=1 \mid T\right)$ are all above 50 percent? A smaller value for $k$ increases the speed at which a turning point might be identified, but increases the chances of calling a false positive. Our first rule is defined for maximum speed, requiring only that a single occurrence of a probability moving from above (below) 50 percent to below (above) 50 percent must be observed before a turning point is determined. Our second rule, consistent with the NBER tradition of not classifying very short downturns or expansions as separate regimes, requires that a recession or expansion last at least 3 months before a new turning point is defined. Note that for real GDP, which is measured quarterly, this requirement is met with only a single occurrence of a probability crossing 50 percent, meaning that rule 1 is identical to rule 2 . For employment data, which is measured monthly, rule 2 requires three consecutive probabilities above (below) 50 percent and will thus differ from rule 1.

Formally, our turning point rules for employ- 


\section{Figure 1}

A. Full-Sample Estimated $P\left(S_{t}=1\right)$ from Markov-Switching Model of Quarterly Real GDP

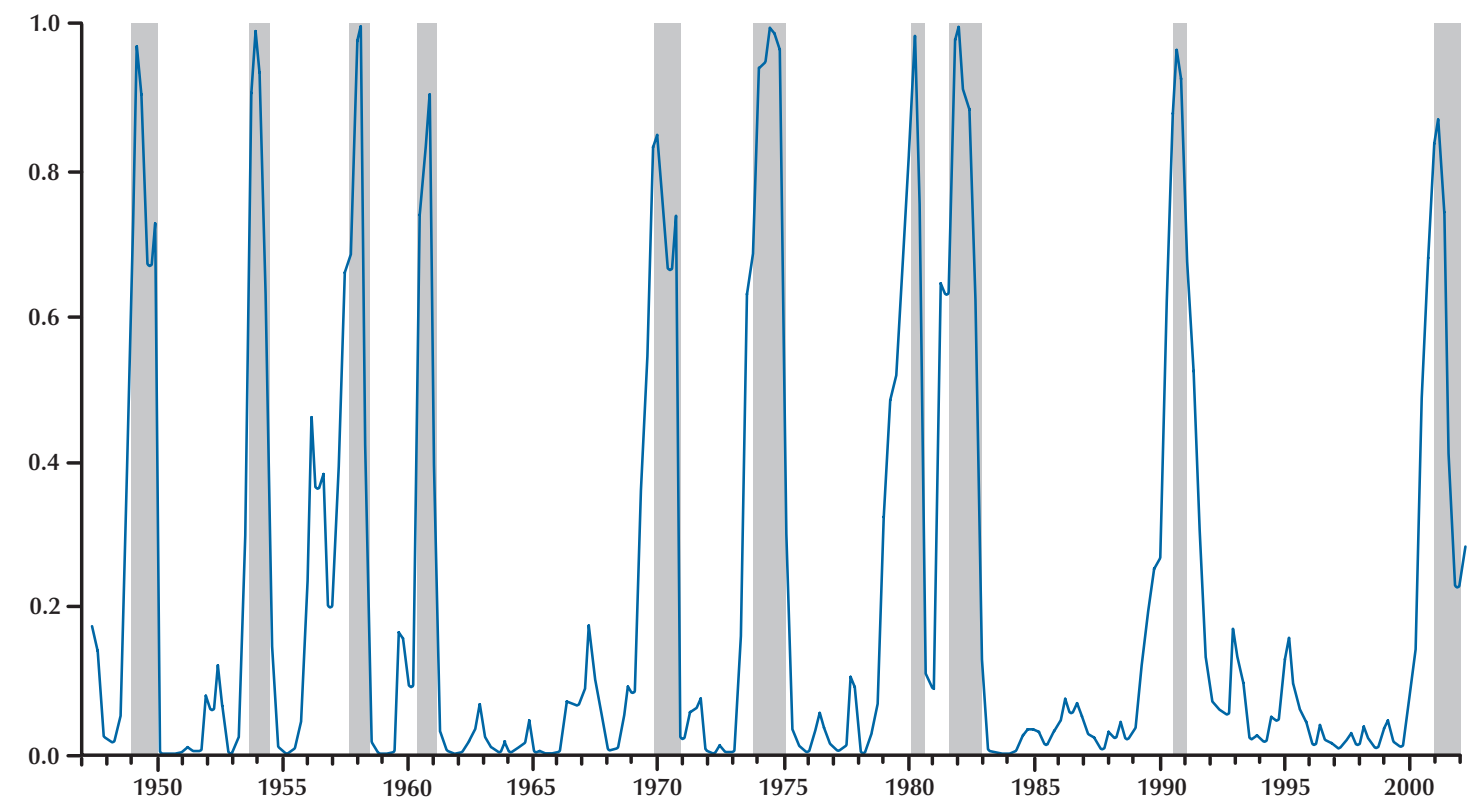

NOTE: Data vintage July 31, 2002. Shaded areas denote NBER recession dates.

B. Full-Sample Estimated $P\left(S_{t}=1\right)$ from Markov-Switching Model of Monthly Nonfarm Payroll Employment

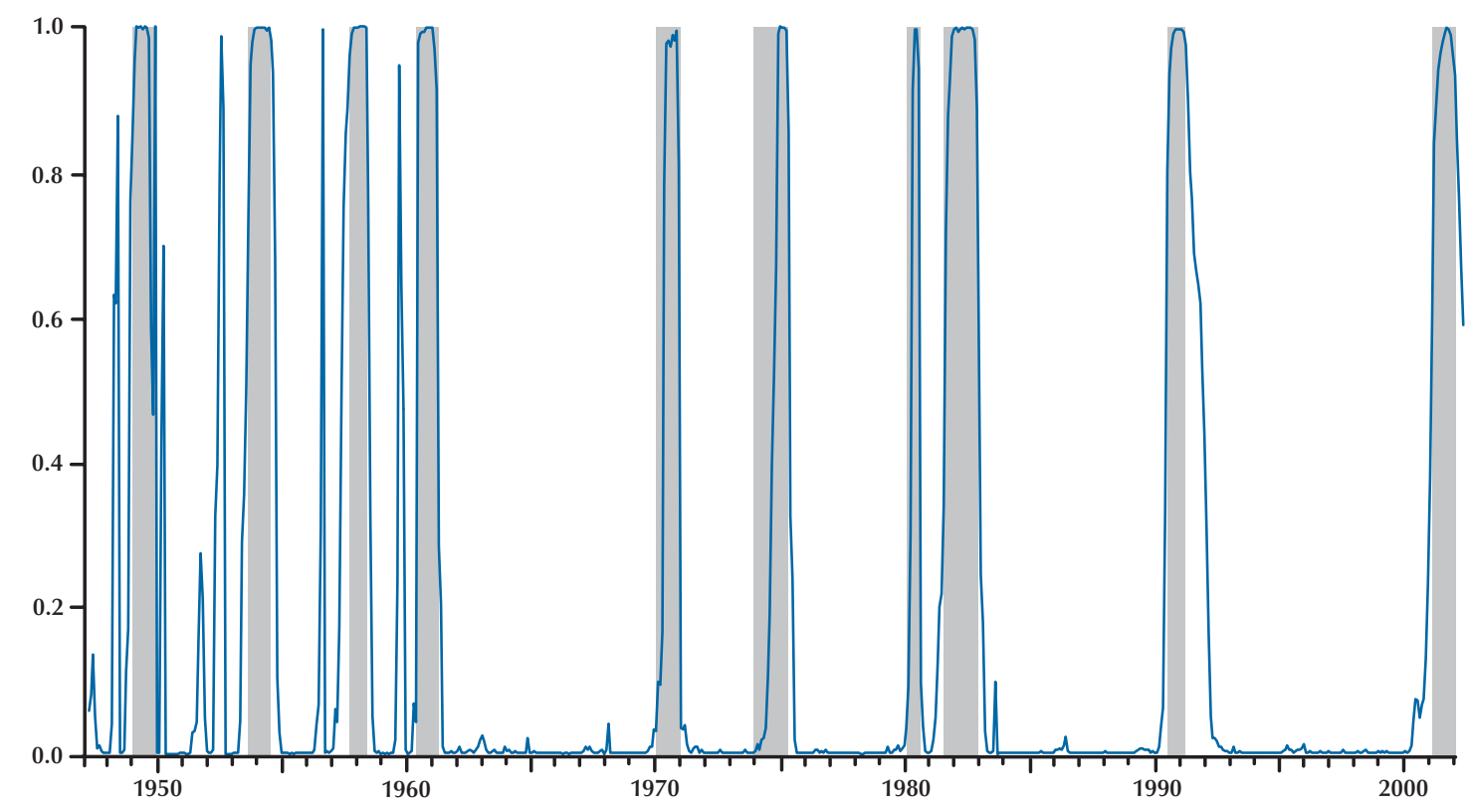

NOTE: Data vintage August 2, 2002. Shaded areas denote NBER recession dates. 
ment and GDP growth can be specified using the following definitions:

Monthly Employment Growth. Definition 1: A business cycle peak is said to occur in month $t+1$ if the economy was in an expansion in month $t$ and

Rule 1: $P\left(S_{t+1}=1\right) \geq 0.5$;

Rule 2: $P\left(S_{t+1}=1\right) \geq 0.5$ and $P\left(S_{t+2}=1\right) \geq 0.5$ and $P\left(S_{t+3}=1\right) \geq 0.5$.

Definition 2: A business cycle trough is said to occur in month $t$ if the economy was in a recession in month $t$ and

Rule 1: $P\left(S_{t+1}=1\right)<0.5$;

Rule 2: $P\left(S_{t+1}=1\right)<0.5$ and $P\left(S_{t+2}=1\right)<0.5$ and $P\left(S_{t+3}=1\right)<0.5$.

GDP Growth. Definition 1: A business cycle peak is said to occur in quarter $t+1$ if the economy was in an expansion in quarter $t$ and $P\left(S_{t+1}=1\right) \geq 0.5$.

Definition 2: A business cycle trough is said to occur in quarter $t$ if the economy was in a recession in quarter $t$ and $P\left(S_{t+1}=1\right)<0.5$.

Table 1A contains the NBER turning point dates and the corresponding dates obtained from the Markov-switching model applied to real GDP growth based on the above definitions. The agreement between the two is striking. The Markov-switching model captures each of the NBER business cycle peaks and troughs in the sample. The average discrepancy between the 10 NBER business cycle peaks and the business cycle peaks from the switching model applied to real GDP growth is approximately 2.4 months, with a maximum discrepancy of 6 months and a standard deviation of 1.8 months. Business cycle troughs are dated even closer. There is no discrepancy on average between the nine NBER business cycle troughs and the business cycle troughs from the switching model (the two dates are the same for six of the nine troughs), with a maximum discrepancy of 6 months and a standard deviation of around 2.7 months. Generally the model tends to determine turning points at or before the ones established by the NBER. The only exception is for the 1990-91 recession trough, for which the switching model dates the trough two quarters after the NBER date.

In addition to capturing each of the NBER business cycle dates, the switching model applied to GDP growth generates no false business cycle dates. That is, for the whole sample, the probability of recession only increased (decreased) above (below) 50 percent near the beginning or end of an actual recession. Thus, for the model applied to real GDP, an increase or decrease in the probability of recession above or below 50 percent sends a very strong signal that a turning point has actually occurred.

Table $1 \mathrm{~B}$ shows the NBER turning point dates and the corresponding dates obtained from the Markov-switching model applied to monthly employment growth under rule 1 defined above. The agreement between the two sets of dates is very close, although somewhat less so than that obtained from GDP. There are two reasons for this. First, we are using employment at the monthly frequency, which is a much more noisy series than quarterly GDP. Second, employment slightly lags the business cycle. Generally employment falls after a recession begins and increases after it ends, as employers are reluctant to fire (or hire) until a recession gains intensity (or there are clear signs of its end). Nevertheless, the switching model applied to monthly employment captures each of the NBER business cycle peaks and troughs in the sample. The average discrepancy between the NBER peaks and the peaks from the switching model is approximately 1 month, with a maximum discrepancy of 9 months and a standard deviation of 3.6 months. Similarly, the average discrepancy between the NBER trough dates and the trough dates from the switching model is 1.8 months, with a maximum discrepancy of 10 months and a standard deviation of 3.2 months.

The trough dates from the switching model applied to employment tend to slightly lag the NBER dates. In particular, all troughs from employment either lag (five of nine) or coincide (four of nine) with the NBER's. The results are mixed for peak dates: Half of the peak dates from the model either coincide or lead the NBER peak dates, whereas half lag the NBER dates.

In addition to the business cycle dates in Table $1 \mathrm{~B}$, turning point rule 1 identified three false-positive business cycle dates, all early in the sample. If the minimum number of consecutive months that $P\left(S_{t}=1 \mid T\right)$ is required to be above (below) 50 percent before a turning point is identified were increased to two, only a single false-positive result occurs (February 1948). Under turning point rule 2 defined above, in which $P\left(S_{t}=1 \mid T\right)$ is required to be above (below) 50 percent for three consecutive months before a turning point is defined, there are no falsepositive results. This is achieved with no tradeoff in terms of missed NBER dates; rule 2 still captures 


\section{Table 1}

Business Cycle Dates-NBER and Markov-Switching Models Estimated Over Full Sample

\begin{tabular}{|c|c|c|c|c|c|}
\hline \multicolumn{3}{|c|}{ Peak } & \multicolumn{3}{|c|}{ Trough } \\
\hline NBER & $\begin{array}{l}\text { Switching } \\
\text { model }\end{array}$ & $\begin{array}{c}\text { Lead/lag } \\
\text { discrepancy }\end{array}$ & NBER & $\begin{array}{l}\text { Switching } \\
\text { model }\end{array}$ & $\begin{array}{c}\text { Lead/lag } \\
\text { discrepancy }\end{array}$ \\
\hline \multicolumn{6}{|l|}{ A. Real GDP } \\
\hline November 1948 & 1948:Q4 & 0 & October 1949 & 1949:Q4 & 0 \\
\hline July 1953 & 1953:Q3 & 0 & May 1954 & 1954:Q2 & 0 \\
\hline August 1957 & 1957:Q2 & 1Q & April 1958 & 1958:Q1 & $1 Q$ \\
\hline April 1960 & 1960:Q2 & 0 & February 1961 & 1960:Q4 & 1Q \\
\hline December 1969 & 1969:Q3 & 1Q & November 1970 & 1970:Q4 & 0 \\
\hline November 1973 & 1973:Q3 & 1Q & March 1975 & 1975:Q1 & 0 \\
\hline January 1980 & 1979:Q3 & $2 \mathrm{Q}$ & July 1980 & 1980:Q3 & 0 \\
\hline July 1981 & 1981:Q2 & $1 \mathrm{Q}$ & November 1982 & 1982:Q4 & 0 \\
\hline July 1990 & 1990:Q2 & $1 \mathrm{Q}$ & March 1991 & 1991:Q3 & $-2 Q$ \\
\hline March 2001 & 2000:Q4 & $1 \mathrm{Q}$ & Not yet announced & 2001:Q3 & - \\
\hline Mean & & $0.8 \mathrm{Q}$ & & & $0.0 \mathrm{Q}$ \\
\hline Median & & $1.0 \mathrm{Q}$ & & & $0.0 \mathrm{Q}$ \\
\hline Standard deviation & & $0.6 \mathrm{Q}$ & & & $0.9 \mathrm{Q}$ \\
\hline
\end{tabular}

\section{B. Nonfarm Payroll Employment}

\begin{tabular}{|c|c|c|c|c|c|}
\hline November 1948 & October 1948 & $1 \mathrm{M}$ & October 1949 & October 1949 & 0 \\
\hline July 1953 & June 1953 & $1 \mathrm{M}$ & May 1954 & August 1954 & $-3 M$ \\
\hline August 1957 & April 1957 & $4 M$ & April 1958 & May 1958 & $-1 M$ \\
\hline April 1960 & May 1960 & $-1 \mathrm{M}$ & February 1961 & February 1961 & 0 \\
\hline December 1969 & April 1970 & $-4 M$ & November 1970 & November 1970 & 0 \\
\hline November 1973 & August 1974 & $-9 M$ & March 1975 & April 1975 & $-1 M$ \\
\hline January 1980 & April 1980 & $-3 M$ & July 1980 & July 1980 & 0 \\
\hline July 1981 & August 1981 & $-1 \mathrm{M}$ & November 1982 & December 1982 & $-1 \mathrm{M}$ \\
\hline July 1990 & July 1990 & 0 & March 1991 & January 1992 & $-10 \mathrm{M}$ \\
\hline March 2001 & February 2001 & $1 \mathrm{M}$ & Not yet announced & Not yet identified & - \\
\hline Mean & & $-1.1 \mathrm{M}$ & & & $-1.8 \mathrm{M}$ \\
\hline Median & & $-0.5 \mathrm{M}$ & & & $-1.0 \mathrm{M}$ \\
\hline Standard deviation & & $3.6 \mathrm{M}$ & & & $3.2 \mathrm{M}$ \\
\hline
\end{tabular}

NOTE: Leads (lags) are represented by $+(-)$ and indicate how many months the switching model anticipates (lags) the NBER dating, whereas 0 indicates that the two dating systems coincide. 
all of the NBER business cycle peaks and troughs in the sample.

\section{Real-Time Business Cycle Dates}

In this section we investigate the real-time performance of the switching model for dating business cycles. This will involve an out-of-sample evaluation of the model's performance. Our out-of-sample period will be the past 40 years of data, with prior data used for initial estimation of the model. We are interested in the following question: Had the switching model been used to date business cycles in the past, how would it have performed? We are particularly interested in the ability of the model to accurately and quickly identify in real time the six NBER peaks and five NBER troughs over this period. We are also interested in the incidence of false business cycle dates, that is, business cycle dates identified by the model that do not correspond to an NBER-dated peak or trough.

There are two features of such a real-time exercise. First, only data over the sample period that the business cycle analyst would have had available at that time should be used. We achieve this first requirement by using a recursive estimation routine. This routine works as follows: We begin with data that extends from the second quarter of 1947 to the third quarter of 1965 for real GDP and from February 1947 to October 1964 for employment. The model is estimated and the probability of a new turning point at the end of the sample evaluated. The sample is then extended by one data point, the model reestimated, and the probability of a turning point evaluated. This process is repeated until the final sample is reached, which extends from the second quarter of 1947 to the second quarter of 2002 for real GDP and from February 1947 to July 2002 for employment.

The second feature of the real-time exercise is to assume no more knowledge of data revisions than what would have been known by an econometrician estimating the model at the time. Thus, for each end-of-sample date in the recursive estimation routine, we use the first available release of these data. For example, for our first sample for real GDP data, which extends from the second quarter of 1947 through the third quarter of 1965 , we use the first release of data that included the third quarter of 1965 . For real GDP these data were available by the beginning of the second month of the fourth quarter of 1965 , which we refer to as the vintage of this dataset. The monthly employment datasets are similar, except they are more timely than the GDP data. In particular, the first release of employment data for a given month is usually available by the first week of the subsequent month. We obtained the real-time datasets for quarterly real GDP and monthly payroll employment from the Federal Reserve Bank of Philadelphia. ${ }^{5}$

In evaluating the evidence for a turning point, we consider the probability of a recession at the end of the sample for that particular vintage, that is, $P\left(S_{T}=1 \mid T\right)$, where $T$ denotes the end of the sample period. This will be referred to as the "real-time recursive probability" throughout the remainder of the paper. Such an estimated probability, which is estimated for time $t$ using time $t$ information, is often called a "filtered" probability. This is, of course, less information than econometricians would have had available to them at the time, as econometricians would also have had the so-called "smoothed" probabilities for prior dates, that is, $P\left(S_{t}=1 \mid T\right)$, where $t<T$. Thus, while the model might miss a turning point at time $t$ for the dataset that ends at time $t$, it might catch this turning point for the dataset that ends at $T$. We do not allow for this possibility in the following, thus placing the model at a disadvantage for dating turning points. However, as will be shown, the model's performance is still quite good despite this disadvantage.

Figures $2 \mathrm{~A}$ and $\mathrm{B}$ plot the real-time recursive probability of a recession at the end of the sample against the NBER business cycle dates. That is, the point on the graph for date $t$ represents the estimated probability of recession at date $t$ for the recursive sample that ended on date $t$. The probabilities are closely related to the NBER turning points, tending to increase or decrease substantially only around NBER peaks and troughs. The real-time recursive probabilities of recession from the employment data are noisier than those from GDP growth, which is not surprising given the higher frequency of the employment data.

We next move to tabulation of business cycle dates using turning point rule 1 for converting probabilities into business cycle dates defined in the section "Full-Sample Business Cycle Dates." Tables 2A and $B$ contain the NBER business cycle peak and trough dates and the corresponding dates identified in real time by the switching model. The top frame of each table evaluates the performance of the model in capturing business cycle peaks. The bottom frame evaluates business cycle troughs. The first column

\footnotetext{
5 See Croushore and Stark (2001) for information regarding this dataset.
} 


\section{Figure 2}

A. Real-Time Recursively Estimated $P\left(S_{t}=1\right)$ from Markov-Switching Model of Quarterly Real GDP

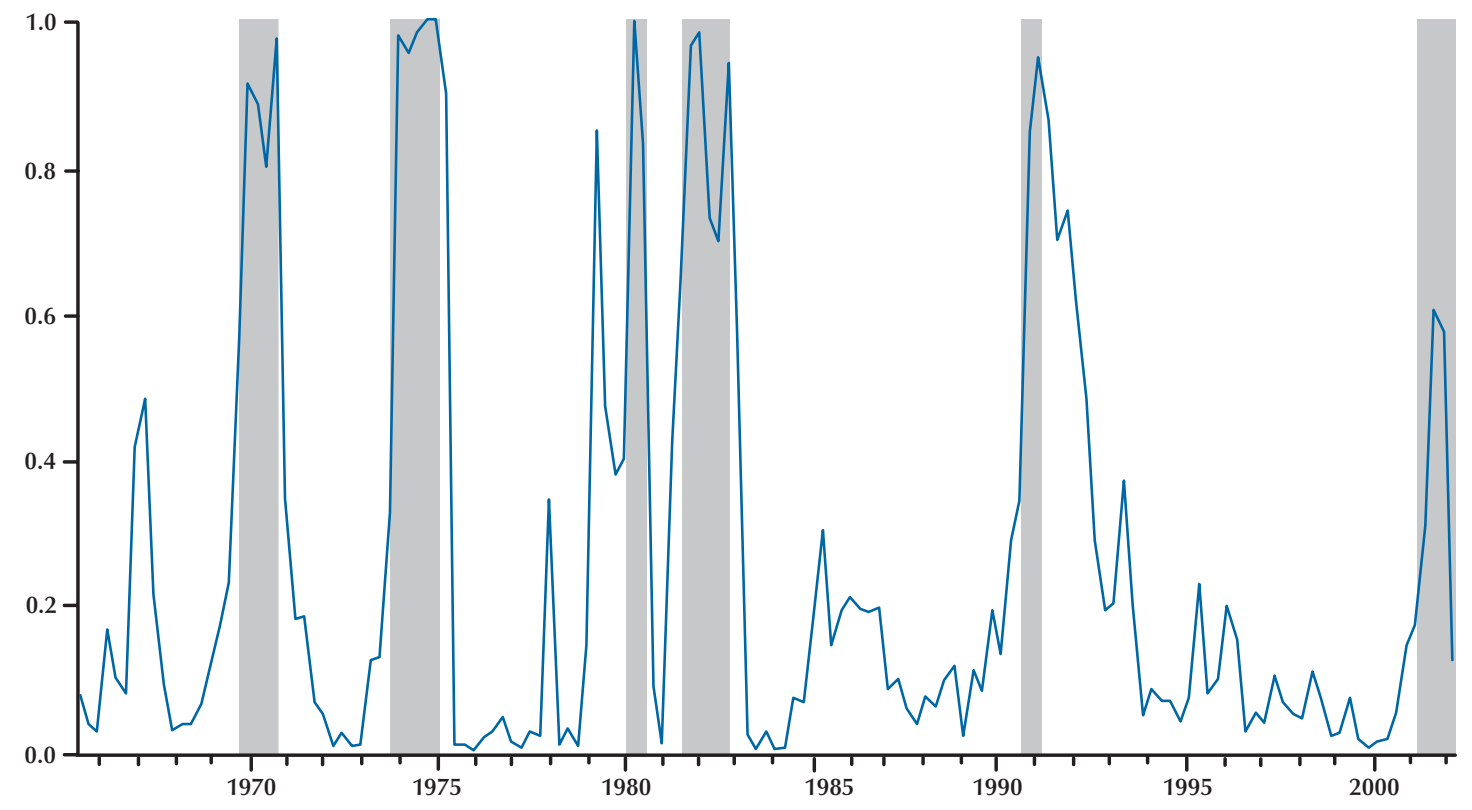

NOTE: Shaded areas denote NBER recession dates.

B. Real-Time Recursively Estimated $P\left(S_{t}=1\right)$ from Markov-Switching Model of Monthly Nonfarm Payroll Employment

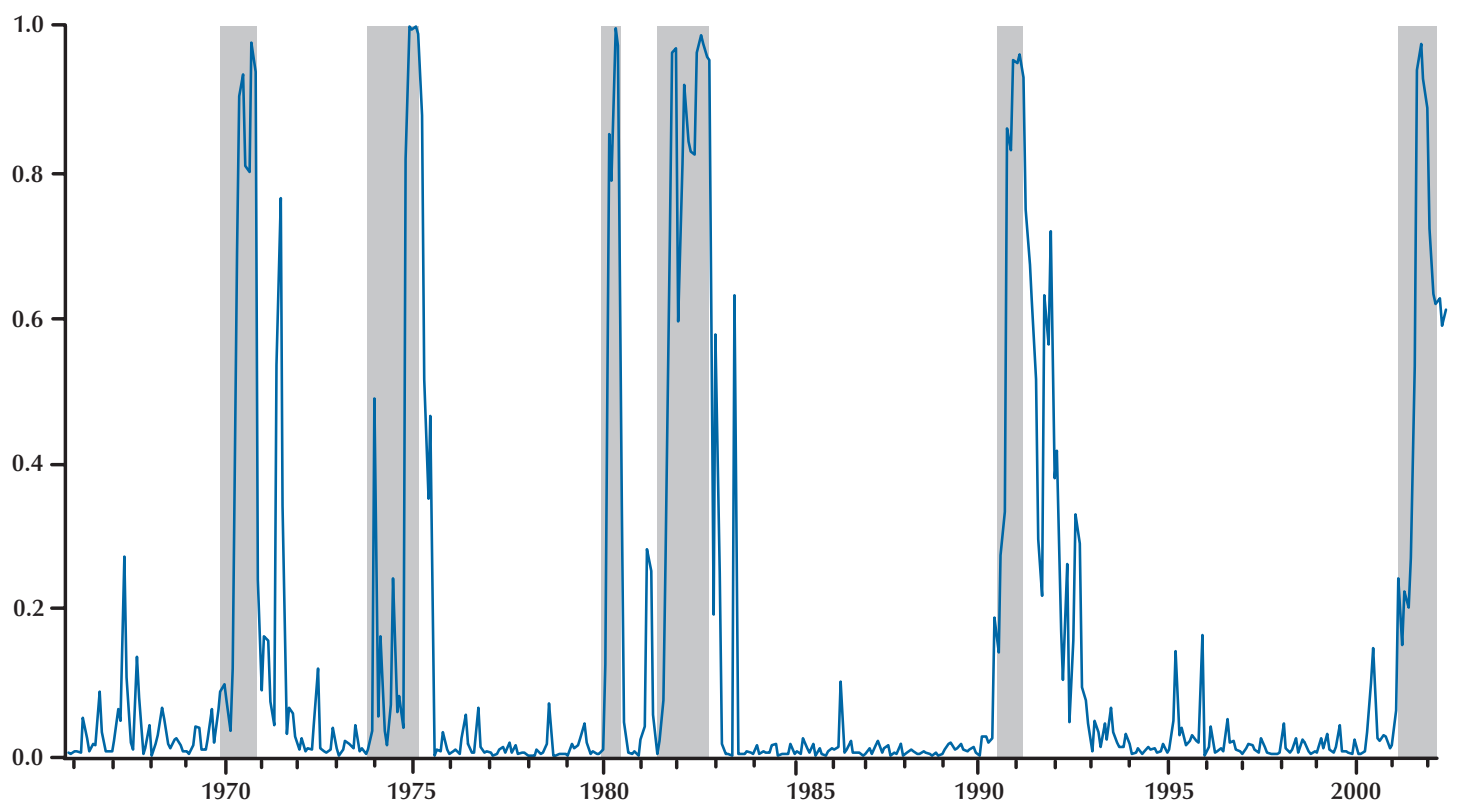

NOTE: Shaded areas denote NBER recession dates. 


\section{Table 2A}

\section{Recession Dates Obtained in Real Time-NBER and Markov-Switching Model of Real GDP Estimated Over Recursive Samples}

\begin{tabular}{|c|c|c|c|c|c|}
\hline $\begin{array}{l}\text { Peak date: } \\
\text { switching model }\end{array}$ & $\begin{array}{c}\text { Peak date } \\
\text { available: } \\
\text { switching model }\end{array}$ & $\begin{array}{l}\text { Peak date: } \\
\text { NBER }\end{array}$ & $\begin{array}{c}\text { Peak date } \\
\text { announced: } \\
\text { NBER }\end{array}$ & $\begin{array}{c}\text { Lead/lag } \\
\text { discrepancy }\end{array}$ & $\begin{array}{c}\text { Lead } \\
\text { announcement } \\
\text { date: } \\
\text { switching model }\end{array}$ \\
\hline 1969:Q4 & February 1970 & December 1969 & - & 0 & - \\
\hline 1974:Q1 & May 1974 & November 1973 & - & $-1 Q$ & - \\
\hline 1980:Q2 & August 1980 & January 1980 & June 3, 1980 & $-1 Q$ & $-2 \mathrm{M}$ \\
\hline 1981:Q3 & November 1981 & July 1981 & January 6, 1982 & 0 & $2 \mathrm{M}$ \\
\hline 1990:Q4 & February 1991 & July 1990 & April 25, 1991 & $-1 Q$ & $2 \mathrm{M}$ \\
\hline 2001:Q3 & November 2001 & March 2001 & November 26, 2001 & $-2 Q$ & 0 \\
\hline Mean & & & & $-0.8 \mathrm{Q}$ & $0.5 \mathrm{M}$ \\
\hline Median & & & & $-1.0 \mathrm{Q}$ & $1.0 \mathrm{M}$ \\
\hline Standard deviation & & & & $0.8 \mathrm{Q}$ & $1.9 \mathrm{M}$ \\
\hline
\end{tabular}

\begin{tabular}{|c|c|c|c|c|c|}
\hline $\begin{array}{l}\text { Trough date: } \\
\text { switching model }\end{array}$ & $\begin{array}{l}\text { Trough date } \\
\text { available: } \\
\text { switching model }\end{array}$ & $\begin{array}{c}\text { Trough date: } \\
\text { NBER }\end{array}$ & $\begin{array}{c}\text { Trough date } \\
\text { announced: } \\
\text { NBER }\end{array}$ & $\begin{array}{c}\text { Lead/lag } \\
\text { discrepancy }\end{array}$ & $\begin{array}{c}\text { Lead } \\
\text { announcement } \\
\text { date: } \\
\text { switching model }\end{array}$ \\
\hline 1970:Q4 & February 1971 & November 1970 & - & 0 & - \\
\hline 1975:Q2 & August 1975 & March 1975 & - & $-1 \mathrm{Q}$ & - \\
\hline 1980:Q3 & November 1980 & July 1980 & July 8, 1981 & 0 & $8 \mathrm{M}$ \\
\hline 1983:Q1 & May 1983 & November 1982 & July 8, 1983 & $-1 \mathrm{Q}$ & $2 \mathrm{M}$ \\
\hline 1992:Q1 & May 1992 & March 1991 & December 22, 1992 & $-4 \mathrm{Q}$ & $7 \mathrm{M}$ \\
\hline 2001:Q4 & February 2002 & $\begin{array}{l}\text { Not yet } \\
\text { announced }\end{array}$ & $\begin{array}{l}\text { Not yet } \\
\text { announced }\end{array}$ & - & - \\
\hline Mean & & & & $-1.2 \mathrm{Q}$ & $5.7 \mathrm{M}$ \\
\hline Median & & & & $-1.0 \mathrm{Q}$ & $7.0 \mathrm{M}$ \\
\hline Standard deviation & & & & $1.6 \mathrm{Q}$ & $3.2 \mathrm{M}$ \\
\hline
\end{tabular}

gives the first date (labeled "Peak date") that a turning point was assigned in real time by the switching model. The second column gives the date this turning point would have first been available. For example, the first entry in the second column of Table $2 \mathrm{~A}$ is February 1970. This is the date at which the business cycle peak of the fourth quarter of 1969 , listed in the first column, would have first been identified using the switching model (as early February is approximately when the first iteration of GDP data for the fourth quarter of 1969 would have been available). The third and fourth columns give the official NBER business cycle dates and when they were announced. Note that the NBER Business Cycle
Dating Committee began dating business cycle peaks and troughs in real time with the 1980 recession. Thus, the dates of these announcements are recorded in the table only from this date on. The fifth column records the discrepancy between the peak or trough date first assigned by the switching model and the corresponding date assigned by the NBER, which is the amount of time the date in column 1 precedes that in column 3 . The final column shows how far in advance of the NBER date the switching model date would have been availablethat is, the amount of time the date in column 2 anticipates that in column 4.

Tables $2 \mathrm{~A}$ and $\mathrm{B}$ demonstrate that the switching 


\section{Table 2B}

\section{Recession Dates Obtained in Real Time-NBER and Markov-Switching Model of Nonfarm} Payroll Employment Estimated Over Recursive Samples

\begin{tabular}{|c|c|c|c|c|c|}
\hline $\begin{array}{l}\text { Peak date: } \\
\text { switching model }\end{array}$ & $\begin{array}{c}\text { Peak date } \\
\text { available: } \\
\text { switching model }\end{array}$ & $\begin{array}{c}\text { Peak date: } \\
\text { NBER }\end{array}$ & $\begin{array}{c}\text { Peak date } \\
\text { announced: } \\
\text { NBER }\end{array}$ & $\begin{array}{c}\text { Lead/lag } \\
\text { discrepancy }\end{array}$ & $\begin{array}{c}\text { Lead } \\
\text { announcement } \\
\text { date: } \\
\text { switching model }\end{array}$ \\
\hline May 1970 & June 1970 & December 1969 & - & $-5 \mathrm{M}$ & - \\
\hline Novemer 1974 & December 1974 & November 1973 & - & $-12 \mathrm{M}$ & - \\
\hline April 1980 & May 1980 & January 1980 & June 3, 1980 & $-3 M$ & $1 \mathrm{M}$ \\
\hline November 1981 & December 1981 & July 1981 & January 6, 1982 & $-4 M$ & $1 \mathrm{M}$ \\
\hline November 1990 & December 1990 & July 1990 & April 25, 1991 & $-4 M$ & $4 M$ \\
\hline September 2001 & October 2001 & March 2001 & November 26, 2001 & $-6 M$ & $1 M$ \\
\hline Mean & & & & $-5.7 \mathrm{M}$ & $1.8 \mathrm{M}$ \\
\hline Median & & & & $-4.5 \mathrm{M}$ & $1.0 \mathrm{M}$ \\
\hline Standard deviation & & & & $3.3 \mathrm{M}$ & $1.5 \mathrm{M}$ \\
\hline
\end{tabular}

\begin{tabular}{|c|c|c|c|c|c|}
\hline $\begin{array}{l}\text { Trough date: } \\
\text { switching model }\end{array}$ & $\begin{array}{c}\text { Trough date } \\
\text { available: } \\
\text { switching model }\end{array}$ & $\begin{array}{c}\text { Trough date: } \\
\text { NBER }\end{array}$ & $\begin{array}{c}\text { Trough date } \\
\text { announced: } \\
\text { NBER }\end{array}$ & $\begin{array}{c}\text { Lead/lag } \\
\text { discrepancy }\end{array}$ & $\begin{array}{c}\text { Lead } \\
\text { announcement } \\
\text { date: } \\
\text { switching model }\end{array}$ \\
\hline November 1970 & December 1970 & November 1970 & - & 0 & - \\
\hline May 1975 & June 1975 & March 1975 & - & $-2 M$ & - \\
\hline July 1980 & August 1980 & July 1980 & July 8,1981 & 0 & $11 \mathrm{M}$ \\
\hline December 1982 & January 1983 & November 1982 & July 8, 1983 & $-1 M$ & $6 \mathrm{M}$ \\
\hline Augugust 1991 & September 1991 & March 1991 & December 22, 1992 & $-5 M$ & $15 M$ \\
\hline July 2002? & $\begin{array}{l}\text { Not yet } \\
\text { identified }\end{array}$ & $\begin{array}{l}\text { Not yet } \\
\text { announced }\end{array}$ & $\begin{array}{l}\text { Not yet } \\
\text { announced }\end{array}$ & - & - \\
\hline Mean & & & & $-1.6 \mathrm{M}$ & $10.7 \mathrm{M}$ \\
\hline Median & & & & $-1.0 \mathrm{M}$ & $11.0 \mathrm{M}$ \\
\hline Standard deviation & & & & $2.1 \mathrm{M}$ & $4.5 \mathrm{M}$ \\
\hline
\end{tabular}

model calls turning point dates in real time that are fairly close to the NBER dates. Table 2A shows the following: For the six NBER peaks in the past 40 years, the switching model applied to real GDP growth yields business cycle dates in real time that were exactly equal to the NBER's in two cases and one or two quarters away in the other cases. The average discrepancy for peaks is 2.4 months with a standard deviation of 2.4 months. For the five NBER business cycle troughs, the trough dates from the model applied to real GDP growth coincide with the NBER dates in two cases and lag one or four quarters in the other cases. The average discrepancy is 3.6 months with a standard deviation of 4.8 months.
For the model applied to employment, Table 2B shows that the real-time probabilities of recession generally lag the NBER turning points, especially in the case of peak dates. The average discrepancy between the model and the NBER peak dates is 5.7 months with a standard deviation of 3.3 months. For trough dates, the average discrepancy is only 1.6 months with a standard deviation of 2.1 months. Tables $2 \mathrm{~A}$ and B demonstrate that the model, when applied to real GDP growth as well as to employment growth, identifies in real time each of the NBER business cycle episodes over the past 40 years. However, this performance would be less impressive if the model also identified numerous 


\title{
Table 3
}

\section{Real-Time Turning Point Signal Error-Markov-Switching Models}

\author{
A. Real GDP Growth \\ Turning point evaluation (6 recessions: 6 NBER peaks, 5 troughs)
}

Correct TP

Missed TP

False TP

B. Employment Growth

Turning point evaluation (6 recessions: 6 NBER peaks, 5 troughs)

Rule 1

Rule 2

Correct TP

11

11

Missed TP

0

False TP

2

0

NOTE: Correct TP refers to prediction of a turning point when an NBER turning point occurs. Missed TP refers to prediction of no turning point when an NBER turning point occurs. False TP refers to prediction of a turning point when no NBER turning point occurs.

other "false" business cycle episodes in real time. Tables $3 \mathrm{~A}$ and B summarize the incidence of such false identifications. From Table 3A, over this 40-year period the dating algorithm applied to real GDP identified only one false business cycle date, in the second quarter of 1979. This increase in the probability of recession signaled an actual slowdown in the U.S. economy in 1979, associated with the second oil shock, and preceded the 1980 recession. From Table 3B, the model applied to employment growth identifies two false business cycle dates using turning point rule 1 . The first of these was in June and July 1971, when the probabilities increased above 50 percent with no corresponding NBER recession. The other false turning point for employment occurs immediately following the 1990-91 recession. Using turning point rule 1, the switching model initially dated the trough of this recession as August 1991. However, $P\left(S_{T}=1 \mid T\right)$ then increased above 50 percent again from November 1991 to January 1992, thus dating a double-dip recession following the 1990-91 recession. Using turning point rule 2, both of these false turning points would have been ruled out, leaving no false business cycle dates. This would not have come at the expense of any missed NBER business cycle episodes, as turning point rule 2 also captured all 11 NBER turning points.

We now turn to the issue of whether the switching model applied in real time would have identified turning points any faster than the NBER Business Cycle Dating Committee. The sixth column of
Tables $2 \mathrm{~A}$ and $\mathrm{B}$, generated using rule 1, suggests that the answer is yes for both peak and trough dates obtained from the model applied to either real GDP or employment growth. Business cycle peak dates were determined an average of 0.5 months and 1.8 months before the NBER announcement, using the model applied to real GDP growth and employment growth, respectively. The model improves on the timeliness of the NBER even more in determining business cycle trough dates. For the three business cycle troughs in the past 25 years, the model applied to GDP would have determined these dates an average of 5.7 months prior to the NBER, with a maximum of 8 months for the 1980 trough. When applied to employment, the model would have determined trough dates an average of 10.7 months prior to the NBER announcements. The model provides a longer lead time when applied to the employment series partially because the employment series is released more quickly than the GDP series.

What should one conclude from the above analysis? We have focused on two evaluation criteria for the regime-switching model: (i) its ability to identify business cycle turning points that correspond to NBER business cycle peaks or troughs and are in fairly close proximity to the NBER dates and (ii) the speed with which the peaks and troughs are identified. Whether one prefers the switching model or to wait for the NBER announcement depends on the relative weight one attaches to each type of performance. If the primary interest is to quickly 
determine whether a recession has begun or ended, the switching model will likely be preferable. If, instead, the primary interest is to obtain the exact NBER date of the business cycle peak or trough, with relatively little weight on the speed with which this is obtained, the switching model will be of less interest. We argue that the switching model presented here provides an improvement in the speed at which NBER business cycle dates are identified, with a reasonable tradeoff in the accuracy of the dates assigned. This performance is impressive given that the model is based on only a single variable.

\section{The 2001 Recession}

The most recent U.S. recession merits further discussion for at least two reasons. First, data revisions in recent months have caused significant revisions in the real-time peak date established by the switching model. Indeed, this revision matches or exceeds the largest seen in the sample period considered in Table 2 . It is worth exploring further the reasons for these large revisions. Second, the trough date for this recession had not yet been established when this paper was written, providing us with an out-of-sample experiment of the usefulness of the switching model.

In November 2001 the NBER Dating Committee dated the peak of the previous expansion as March 2001. In contrast, the real-time recursive probability of a recession, given by $P\left(S_{T}=1 \mid T\right)$, first rose above 50 percent in the third quarter of 2001 for the model applied to real GDP and in September 2001 for the model applied to employment growth (Tables $2 \mathrm{~A}$ and $B$ ). A more detailed look at these recession probabilities is given in the first column of Tables $4 \mathrm{~A}$ and $B$ and shows the real-time recursive probability of a recession at each date over the past several years.

The recent large revisions in GDP and employment data changed the peak date obtained from the switching model. The second column of Tables 4A and $B$ show the smoothed probability of a recession using the most recent data available, which was the July 31, 2002, vintage for real GDP and the August 2, 2002, vintage for employment. Using this data, the switching model dates the recession as beginning much earlier, in the fourth quarter of 2000 for real GDP growth and in February 2001 for employment growth. The large revision in the peak date stems from recent data revisions that indicated significantly slower growth than previously recorded for the first six months of 2001. For example, the release of real GDP data dated June 27, 2002, from
Table 4

Probabilities of Recession from MarkovSwitching Models

\begin{tabular}{lcc} 
Period & $\begin{array}{c}\text { Recursive in } \\
\text { real time (percent) }\end{array}$ & $\begin{array}{c}\text { Full sample } \\
\text { using revised data }\end{array}$ \\
\hline $\begin{array}{l}\text { A. Applied to GDP Growth (percent) } \\
\text { 2000 }\end{array}$ & \\
Q1 & 1.6 & 7.8 \\
Q2 & 1.9 & 14.2 \\
Q3 & 0.5 & 48.7 \\
Q4 & 14.6 & 67.8 \\
2001 & & \\
Q1 & 17.4 & 83.6 \\
Q2 & 30.9 & 86.9 \\
Q3 & 60.4 & 74.2 \\
Q4 & 57.3 & 41.0 \\
$\mathbf{2 0 0 2}$ & & \\
Q1 & 12.7 & 22.9 \\
Q2 & 28.4 & 28.4 \\
\hline
\end{tabular}

B. Applied to Employment Growth (percent)

2001

\begin{tabular}{lrl} 
Jan & 1.1 & 36.3 \\
Feb & 1.5 & 50.0 \\
Mar & 6.4 & 68.2 \\
Apr & 24.4 & 85.0 \\
May & 15.2 & 89.8 \\
Jun & 22.6 & 94.2 \\
Jul & 20.3 & 96.3 \\
Aug & 27.2 & 97.8 \\
Sep & 53.4 & 99.1 \\
Oct & 94.0 & 99.8 \\
Nov & 97.6 & 99.7 \\
Dec & 92.8 & 98.8 \\
2002 & & \\
Jan & 88.8 & 96.4 \\
Feb & 72.2 & 94.2 \\
Mar & 63.3 & 88.0 \\
Apr & 61.9 & 81.6 \\
May & 62.8 & 73.8 \\
Jun & 59.0 & 66.4 \\
Jul & 61.2 & 61.2 \\
\hline
\end{tabular}


the Bureau of Economic Analysis recorded quarterly annualized growth of 1.3 and 0.3 percent for the first and second quarters of 2001, respectively. However, the data released on July 31, 2002, instead recorded declines in GDP of 0.6 and 1.6 percent in these quarters. These data revisions altered the peak date established by the switching model, pushing it much earlier - into late 2000 and early 2001.

Again, at the time this paper was written, the NBER had not yet dated the end of the 2001 recession. However, the switching model applied to real GDP growth has already dated the business cycle trough. The real-time probabilities indicate that the end of the recession occurred in the fourth quarter of 2001. This date would have been available with the initial release of the fourth quarter 2001 GDP data, in February 2002. Using the revised GDP data released in late July, the model dates the trough even earlier, in the third quarter of 2001. Using data up to the August 2, 2002, vintage, the switching model applied to employment growth had not yet dated the end of the recession.

\section{CONCLUSIONS}

In this paper we have explored the real-time performance of a Markov-switching model applied to real GDP and employment data for replicating the NBER business cycle chronology over the past 40 years. The model produces business cycle peak and trough dates that are fairly close to the NBER dates, using only information that would have been available at the time the dates were initially established. An important feature of the model is that it generally determines turning-point dates more quickly than the NBER Business Cycle Dating Committee. This timing advantage can be large, especially for business cycle troughs. It accomplishes this performance with a minimum of "false positive" business cycle peak or trough dates over the 40-year period.

Overall, the evidence presented above suggests that a statistical regime-switching model, such as the one used in this paper, could be a useful supplement to the NBER Business Cycle Dating Committee for establishing turning point dates. It appears to capture the features of the NBER chronology accurately and swiftly; furthermore, the method is transparent and consistent. It would be interesting to evaluate the real-time performance of multivariate switching models that incorporate another feature of NBER recessions, comovement across many economic variables over the business cycle, to see whether additional improvements can be made. We leave this for future research.

\section{REFERENCES}

Albert, James H. and Chib, Siddhartha. "Bayes Inference via Gibbs Sampling of Autoregressive Time Series Subject to Markov Mean and Variance Shifts." Journal of Business and Economic Statistics, January 1993, 11(1), pp. 1-15.

Beaudry, Paul and Koop, Gary. "Do Recessions Permanently Change Output?" Journal of Monetary Economics, April 1993, 31(12), pp. 149-63.

Boldin, Michael D. "Dating Turning Points in the Business Cycle.” Journal of Business, 1994, 67(1), pp. 97-130.

Burns, Arthur F. and Mitchell, Wesley E. Measuring Business Cycles. New York: National Buruea of Economic Research, 1946.

Chauvet, Marcelle. "An Econometric Characterization of Business Cycle Dynamics with Factor Structure and Regime Switching." International Economic Review, November 1998, 39(4), pp. 969-96.

Croushore, Dean and Stark, Tom. "A Real-Time Data Set for Macroeconomists." Journal of Econometrics, November 2001, 105(1), pp. 111-30.

Diebold, Francis X. and Rudebusch, Glenn D. "Measuring Business Cycles: A Modern Perspective." The Review of Economics and Statistics, February 1996, 78(1), pp. 67-77.

Friedman, Milton. Monetary Studies of the National Bureau, the National Bureau Enters its 45th Year, 44th Annual Report. New York: National Bureau of Economic Research, 1964, pp. 7-25. Reprinted in Friedman, Milton. The Optimum Quantity of Money and Other Essays. Chicago: Aldine, 1969.

"The 'Plucking Model' of Business Fluctuations Revisited.” Economic Inquiry, April 1993, 31(2), pp. 171-77.

Gavin, William T. and Kliesen, Kevin L. "Unemployment Insurance Claims and Economic Activity." Federal Reserve Bank of St. Louis Review, May/June 2002, 84(3), pp. 15-28.

Hamilton, James D. "A New Approach to the Economic Analysis of Nonstationary Time Series and the Business Cycle." Econometrica, March 1989, 57(2), pp. 357-84.

1994. Time Series Analysis. Princeton University, 
Hansen, Bruce E. “The Likelihood Ratio Test Under Nonstandard Conditions: Testing the Markov-Switching Model of GNP." Journal of Applied Econometrics, OctoberDecember 1992, 7(Suppl 0), pp. S61-S82.

Kim, Chang-Jin; Morley, James and Piger, Jeremy. "Nonlinearity and the Permanent Effects of Recessions." Working Paper 2002 1014, Federal Reserve Bank of St. Louis, October 2002.

and Nelson, Charles R. "Friedman's Plucking Model of Business Fluctuations: Tests and Estimates of Permanent and Transitory Components." Journal of Money, Credit, and Banking, August 1999, 31(3), pp. 317-34.

and Yoo, Ji-Sung. "New Index of Coincident Indicators: A Multivariate Markov Switching Factor Model Approach." Journal of Monetary Economics, December 1995, 36(3), pp. 607-30.

Layton, Allan P. "Dating and Predicting Phase Changes in the U.S. Business Cycle.” International Journal of Forecasting, September 1996, 12(3), pp. 417-28.

McConnell, Margaret M. "Rethinking the Value of Initial Claims as a Forecasting Tool." Federal Reserve Bank of New York Current Issues in Economics and Finance, November 1998, 4(11), pp. 1-6.

Moore, Geoffrey H. and Zarnowitz, Victor. "The Development and Role of the National Bureau of Economic Research's Business Cycle Chronologies," in Robert J. Gordon, ed., The American Business Cycle: Continuity and Change. Chicago: University of Chicago Press, 1986.

Sichel, Daniel. E. "Inventories and the Three Phases of the Business Cycle." Journal of Business and Economic Statistics, July 1994, 12(3), pp. 269-77. 
